UDC 613.2

DOI: $10.21668 /$ health.risk/2020.1.11.eng

\title{
ISOLATION AND IDENTIFICATION OF $\beta$-LACTAMASE PRODUCING PSEUDOMONAS SPP. IN READY-TO-EAT RAW VEGETABLES
}

\author{
Nguyen Thanh Trung ${ }^{1,2}$, Huong Nguyen Minh ${ }^{2}$, Pham Thi Loan ${ }^{1}$, \\ Le Thi Hong Hao', Ta Thi Yen ${ }^{1}$ \\ ${ }^{1}$ National Institute for Food Control, 65 Pham Than Duat Str., Hanoi, Vietnam \\ ${ }^{2}$ Institute of Biotechnology, Vietnam Academy of Science and Technology, 18 Hoang Quoc Viet 1, Cau Giay, \\ Hanoi, Vietnam
}

Contamination of antibiotic-resistant bacterial pathogens in raw food is becoming an increased health risk in numerous countries, including Vietnam where raw herbs and vegetables are used daily in many dishes as a flavor enhancer and a source of vitamin and nutrients. However, raw vegetables can also be a reservoir of various foodborne pathogens such as Pseudomonas spp. and Enterobacteriaceae. In this study, we evaluated the extent of Pseudomonas spp. contamination in 180 ready-to-eat (RTE) vegetables samples from restaurants in Hanoi, examined their antibiotic susceptibility profiles and determined the ability to produce $\beta$-lactamase enzymes of Pseudomonas spp. strains. Our results showed that $21.67 \%(n=39)$ of ready-to-eat vegetables samples in Hanoi were contaminated with Pseudomonas spp.. Of those, sixteen samples were determined to be $\beta$-lactamase producing strains including Pseudomonas putida, P. mendocina and P. aeruginosa. Further analysis revealed six strains (37.50\%) producing extended spectrum $\beta$-lactamase (ESBL) enzyme, five strains $(31.25 \%)$ producing ampC $\beta$-lactamase enzyme and five strain $(31.25 \%$ ) producing both ESBL and ampC $\beta$-lactamases. It can be concluded that ready-to-eat vegetables in Hanoi would be a source of contamination of $\beta$-lactamase producing Pseudomonas spp. that could pose a threat to public health in the community.

Keywords: food, ready-to-eat vegetables, contamination of antibiotic-resistant bacterial pathogens, Pseudomonas spp., health risks.

Ready-to-eat raw vegetables have become a favorable product among many consumers thanks to their high vitamin contents and low energy. In Vietnam, vegetables are common food in the daily life. According to the World Bank's report (2017), the consumption rate of vegetables in Vietnam is $0.4 \mathrm{~kg} / \mathrm{day} /$ person, therefore, it can be estimated that 2,800 tons of vegetables are consumed everyday in Hanoi [1]. With a consumption of about 1 million tons per year, Hanoi must use supplies from vicinity provinces in the Red River Delta. However, vege- tables can become a source of bacterial contamination to animals and humans due to polluted irrigation water and improper washing before they are sold at a marketplace. Thus, it is difficult to control hygiene and monitor safety for food product.

Pseudomonas spp. are versatile gramnegative bacteria that occur in various habitats such as soil, water and living organisms including animals, insects and human. In the genus, $\mathrm{P}$. aeruginosa are a risk to human health as they cause serious diseases such as septicemia, liver damage or necrosis at in-

(C) Nguyen Thanh Trung, Huong Nguyen Minh, Pham Thi Loan, Le Thi Hong Hao, Ta Thi Yen, 2020

Nguyen Thanh Trung - Associate Professor, PhD, Head of Laboratory of food microbiology and genetically modified food (e-mail: trungnt@nifc.gov.vn; tel.: +8 (434) 936-32-69; ORCID: https://orcid.org/0000-0002-8732-9911).

Huong Nguyen Minh - Associate Professor (e-mail: nguyen.huong.m@gmail.com; tel.: +8 (491) 556-24-85; ORCID: https://orcid.org/0000-0001-5302-2973).

Pham Thi Loan - Researcher at the Laboratory of food microbiology (e-mail: trang2103@gmail.com; tel.: +8 (498) 536-43-52; ORCID: https://orcid.org/0000-0002-2315-9722).

Le Thi Hong Hao - PhD, Managing Director (e-mail: lethihonghao@yahoo.com; tel.: +8 (490) 424-81-67; ORCID: https://orcid.org/0000-0003-3570-8570).

Ta Thi Yen - Researcher at the Laboratory of food microbiology (e-mail: yenta@gmail.com; tel.: +8 (490) 495-90-50; ORCID: https://orcid.org/0000-0002-3364-4887). 
jured sections. Other Pseudomonas species including P. fluorescens, P. luteola, P. putida, and $P$. stutzeri possess lower toxicity, but they can cause many infectious diseases in immune-compromised patients [2, 3]. Pseudomonas spp. often invade host tissue and cause infection and septicemia in immune-compromised hosts such as patients suffering from HIV/AIDS, cystic fibrosis, bronchiectasis and severe chronic obstructive pulmonary, burn, or patients after malignant or urinary removal [4]. Recently, pathogenic Pseudomonas spp. have become one of the prominent public health concerns due to their fast-evolving multi-drug resistance. Studies on disease treatment in patients show difficulties in combatting high multidrug resistant Pseudomonas spp. [5].

Studies on bacteria extracted from raw vegetables sold at different markets and restaurants that have antibiotic resistant agents have been previously reported [5]. The prominent group of antibiotic resistant bacteria contaminants from raw vegetables is Pseudomonas spp. They are well known to have multiple antibiotic resistances due to gene scarring genetic factors that originated from other Gram-negative bacilli families such as Enterobacteriaceae through gene exchange [6]. Among these, the $\beta$-lactamase producing strains especially extendedspectrum $\beta$-lactamase (ESBL) and plasmidencoded $\beta$-lactamase $(\mathrm{AmpC})$ producers are of greatest interest. The emergence and spread of $\beta$-lactamase have become a significant global health problem, as they inactivate a wide group of antibiotics used in various hospital treatments [3]. However, until now, there have been no data on Pseudomonas spp. and $\beta$-lactamase producing Pseudomonas spp. in ready-to-eat vegetables in Vietnam. In this study, we aim to evaluate the presence of $\beta$-lactamase producing Pseudomonas spp. in ready-to-eat raw vegetables from restaurants in Hanoi.

Materials and methods. Vegetables sampling. A total of 180 ready-to-eat raw vegetables samples were collected at restaurants in six urban districts of Hanoi from July to October, 2018. Six districts including CauGiay, Hoang Mai, Ha Dong, Dong $\mathrm{Da}$, Hai Ba Trung, Long Bien were selected based on the high rate of population. After being acquired from restaurants, vegetables samples were finely-sliced without any further washing but brown-leaf removing. For every sample, the amount of 25 grams of sample was added into $225 \mathrm{~mL}$ of buffered peptone water (BD, America). The mixture was then homogenized for 30 seconds using a homogenizer. Weight 25 grams of each finely-sliced leaf-sample and homogenizing for 30 seconds using homogenizer. The mixtures were then diluted to desired concentration by using peptone $(0.1 \%)$ saline diluent.

Bacterial isolation and identification. Pseudomonas spp. are extracted with a conventional method according to ISO 13720: 2010 [7]. Briefly, $0.1 \mathrm{~mL}$ of homogenized sample was spread on Pseudomonas CFC/CN (Merck, Germany) agar supplemented with CFC Selective supplement (Merck, Germany) and the plates were incubated under aerobic conditions at $25^{\circ} \mathrm{C}$ for $44 \pm 4$ hours. After incubation, colonies were confirmed using Oxidase Strips (Merck, Germany). Oxidasepositive colonies identified as Pseudomonas spp. E. coli ATCC25922 (ATCC, America) were used as negative control while P. aeruginosa ATCC 27853 (ATCC, America) strain was used as the positive control. Confirmed Pseudomonas spp. strains were further analyzed using Vitek ${ }^{\circledR} \mathrm{MS}$ system (BioMerieux, France) to identify their species. Vitek ${ }^{\circledR}$ MS procedure was performed according to manufacturer's recommendations.

Identification of $\beta$-lactamase producing Pseudomonas spp. To determine Pseudomonas spp. producing $\beta$-lactamase, susceptibility testing with disc diffusion method was performed and interpreted following the technique recommended by the World Health Organization and the guidelines by 
the American Institute for Testing and Clinical Standards (CLSI) [8, 9]. The antibiotics being examined included cefotaxime (CTX, Liofilchem, Italy), cefotaxime combined with clavulanic acid (CTL, Liofilchem, Italy), ceftazidime (CAZ, Liofilchem, Italy) and ceftazidime combined with clavulanic acid (CAL, Liofilchem, Italy). The strains are confirmed to be extended-spectrum $\beta$-lactamase (ESBL) producing ones when the observed CTL or/and CAL resistance zones are at least $5 \mathrm{~mm}$ greater than the observed CTX and CAZ resistance zones.

The presence of AmpC $\beta$-lactamase enzyme was determined by testing strains against cefotaxime (CTX, Liofilchem, Italy), cefotaxime combined with cloxacillin (CTC, Liofilchem, Italy), ceftazidime (CAZ, Liofilchem, Italy) and ceftazidime combined with cloxacillin (CAC, Liofilchem, Italy) following CLSI guidelines. When the observed CTC or/and CAC resistance zones are at least $5 \mathrm{~mm}$ greater than the observed CTX and $\mathrm{CAZ}$ resistance zones, the tested bacteria are confirmed to be AmpC $\beta$-lactamase producing strains.

Results and discussions. Pseudomonas spp. in raw vegetables. The obtained results revealed that 39 over 180 samples of ready-toeat vegetables collected at restaurants (Grilled duck, bun cha, bread, spring rolls, pho, vermicelli, and noodle) were found to be positive with Pseudomonas spp. assuming oxidase- positive colonies. The finding of this study revealed that Pseudomonas spp. were prevalent (Figure 1).The difference in Pseudomonas spp. prevalence among sampling locations (districts) was not significant $(\mathrm{P}>0.05)$.

Similar to our results, the prevalence of Pseudomonas spp. on ready-to-eat vegetable was also reported in former studies in several countries such as Italy $(n=24)$, India $(n=12$ isolates were collected from tomato, cucumber and potato), and Nigeria $(n=82)[5,10$, 11]. Pseudomonas spp. are known to be the most common bacteria involved in spoilage of many kinds of foods, due to their very simple nutritional requirements and metabolic versatility that allows them to live in variable environments. The soil and irrigation water contamination may cause the prevalence of Pseudomonas spp. in ready-to-eat vegetable. Numerous studies have demonstrated that water plays important role in directly introducing bacteria into food during pre-harvest and postharvest stages [12-14]. It is during the pre-harvest phase that vegetable might be contaminated with Pseudomonas spp. due to infected irrigation water. Furthermore, for postharvest processes, ranging from storage and washing before selling, might lead to contamination.

Identified Pseudomonas spp. by using Vitek $\AA M S$. The obtained colonies were identified on the Vitek ${ }^{\circledR M S}$. We detected 3 strains of Pseudomonas spp. including opportunistic

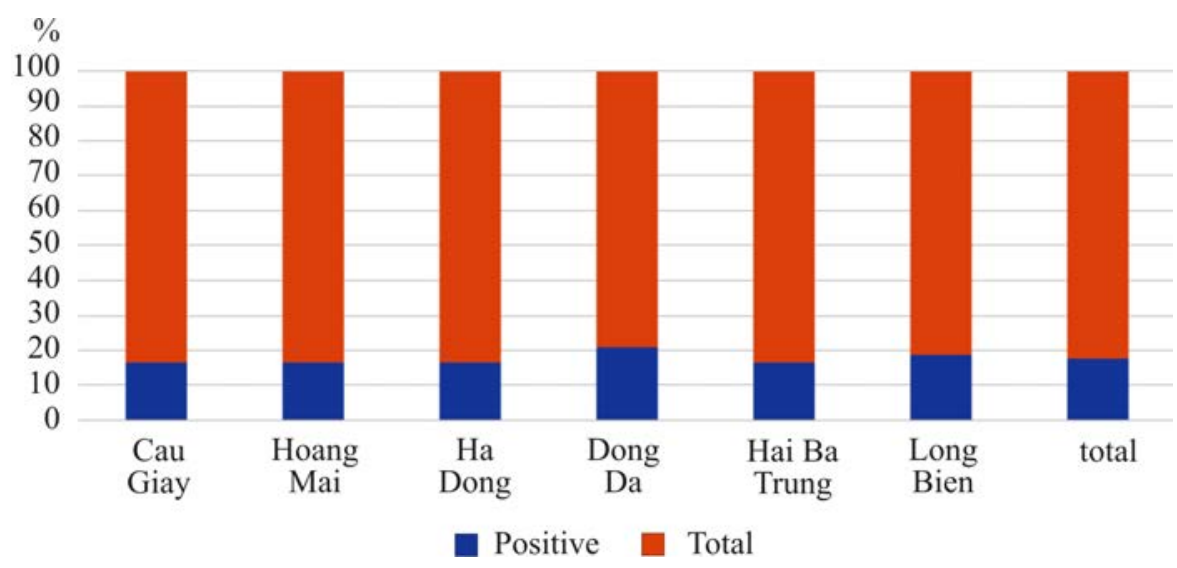

Figure 1. Percentage bar chart illustrating the prevalence of Pseudomonas spp. on ready-to-eat vegetable in restaurant in Hanoi 
pathogens (Pseudomonas aeruginosa, Pseudonasmendocina and Pseudomonas putida). Among them, P. putidaare accounted for the majority with 36 out of 39 strains (92\%). There were also 2 strains of $P$. aeruginosa $(5 \%)$ and 1 strain of $P$. mendocina (3\%) (Figure 2).

The identification results show a similarity of more than $90 \%$ compared to the source library of the VITEK MS identifier system, from $99.4 \%$ to $99.9 \%$ for $P$. putida and $99.9 \%$ for $P$. aeruginosa and $P$. mendocina (Figure 3).

The results in this study are similar to those obtained in the previous research on Pseudomonas spp. presence in raw vegetables by Caldera et. al. (2016), and the study by Franzetti et. al. performed on vegetable samples collected in Milan in 2007 as well $[10,15]$. Another study conducted by Devarajan et. al. (2017) in Congo, India and Switzerland revealed occurrence of 141 strains of Pseudomonas spp. in untreated hospital wastewater samples and domestic wastewater sources; P. putida (42\%) and $P$. aeruginosa (39\%) were the majority in detected Pseudomonas spp. Another study by Kittinger et. al. conducted in 2016 on water of the Danube river (Austria) showed that $66.0 \%(n=520)$ isolates were identified as Pseudomonas putida and $27.1 \%$ were Pseudomonas fluorescens, 2 Pseudomonas aeruginosas strains, and less than five other Pseudomonas strains. A large number of Pseudomonas spp. was also found in raw and fermented vegetables in previous studies [16, 17]. The presence of animal dung containing Pseudomonas spp. used as a fertilizer or accidentally in the soil can be a source of contamination of Pseudomonas spp. on vegetables. Moreover, in most developing countries as well as Vietnam, wastewater is discharged from sewage directly into rivers and lakes that are used as irrigation water sources for cultivation, leading to Pseudomonas spp. occurrence in raw vegetable products. Meanwhile, should improper cleaning steps be applied at restaurants they are not effective enough and don't allow removing bacteria from food products making ready-to-eat vegetables infected.

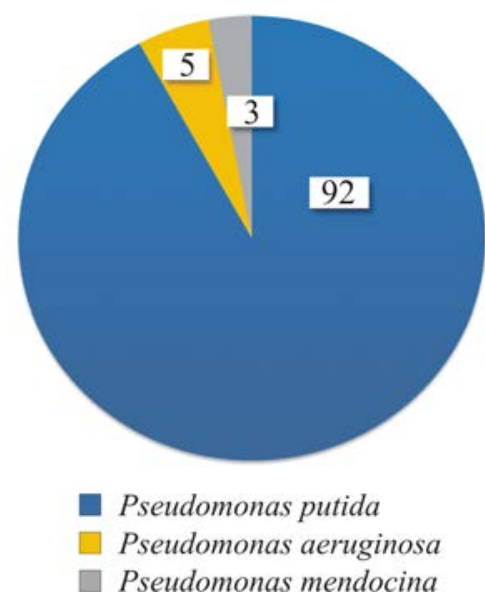

Figure 2. Percentage of Pseudomonas spp. isolates in this study

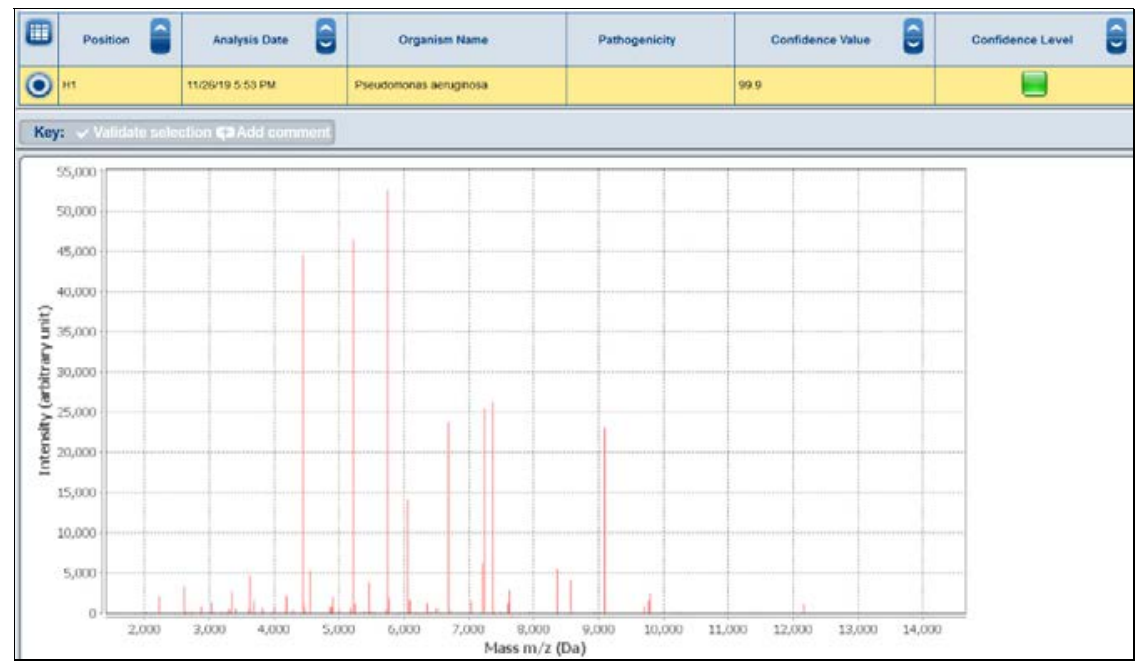

Figure 3. Pseudomonas aeruginosa spectrum of isolate from ready-to-eat vegetable 
Table 1

Pseudomonas spp. producing $\beta$-lactamase enzyme

\begin{tabular}{|c|c|c|c|c|c|}
\hline $\begin{array}{c}\text { Pseudomonas } \\
\text { spp. }\end{array}$ & District & Vegetables & ESBL & AmpC & $\begin{array}{c}\text { ESBL } \\
\& A m p C\end{array}$ \\
\hline P. aeruginosa & \multirow{3}{*}{ CauGiay } & Saw-leaf, Perilla leaf, Vietnamese basil & + & + & + \\
\hline P. putida & & Thai basil & + & - & - \\
\hline P. putida & & Buttercrunch lettuce, Vietnamese basil, Mint leaf & + & + & + \\
\hline P. putida & \multirow{3}{*}{$\begin{array}{l}\text { Hoang } \\
\text { Mai }\end{array}$} & Perilla leaf, mint leaf & - & + & - \\
\hline P. putida & & Vietnamese Balm, Perilla leaf, mint leaf, cucumber & + & - & - \\
\hline P. putida & & Cilantro, Vietnamese Balm, Buttercrunch lettuce & - & + & - \\
\hline P. putida & \multirow{2}{*}{ Ha Dong } & Mint leaf, Buttercrunch lettuce & + & - & - \\
\hline P. putida & & Vietnamese Balm, Buttercrunch lettuce & - & + & - \\
\hline P. putida & \multirow{3}{*}{ Dong Da } & Mint leaf, Lettuce, Vietnamese Balm & + & - & - \\
\hline P. putida & & Buttercrunch lettuce, Perilla leaf, Cilantro & - & + & - \\
\hline P. putida & & Green Onion, Mint leaf & + & + & + \\
\hline P. putida & \multirow{2}{*}{$\begin{array}{l}\text { Hai Ba } \\
\text { Trung }\end{array}$} & Thai basil, Saw-leaf & + & + & + \\
\hline P. aeruginosa & & Thai basil, Saw-leaf & + & + & + \\
\hline P. putida & \multirow{3}{*}{$\begin{array}{l}\text { Long } \\
\text { Bien }\end{array}$} & Cilantro, Green onion & + & - & - \\
\hline P. putida & & Buttercrunch lettuce & - & + & - \\
\hline P. putida & & Buttercrunch lettuce, Perilla leaf & + & - & - \\
\hline
\end{tabular}

Note: + Positive

- Negative

3.3 Pseudomonas spp.producing $\beta$-lactamase enzyme. 39 identified strains of Pseudomonas spp. were used for antimicrobial testing corresponding to each $\beta$ lactamase enzyme. The results showed that 16 strains of Pseudomonas spp., which were detected in vegetables from restaurants in 6 districts, produced $\beta$-lactamase enzyme, of which 6 strains produced an expanded spectrum of $\beta$-lactamase enzyme (ESBL), 5 Pseudomonas strains produced enzyme $\beta$-lactamase AmpC, and 5 strains produced enzyme ESBL and AmpC as well. Whole 16 strains, were $P$. putida and $P$. aeruginosa, in which 2 P. aeruginosa and 3 Pseudomonas putida produced both ESBL and $\beta$-lactamase enzyme (Table 1).

In the study conducted in Nigeria in 2016 by Odumosu et. al. $P$. aeruginosa were detected in 54 out of 82 vegetable samples; 10 out of these 54 strains were identified with ESBL enzymes [5]. The result of Odumosu's study is higher than ours, due to the difference in geography, sample size, conditions of cultivation and sanitation as well. Despite of the fact that ready-to-eat vegetables are a good source of vitamins and nutrients, they can also be a source of pathogenic contamination hazardous for humans and transfer antibioticresistant bacteria to them.

Conclusion. The study showed prevalence of 16 Pseudomonas spp. strains producing $\beta$-lactamase enzyme in 180 samples of readyto-eat vegetables collected in Hanoi. The number of Pseudomonas member found in ready-toeat vegetable in our study was lower than in former studies from some countries worldwide. The difference in geography, sample size and sample collection location might lead to different results among studies.

It is necessary to conduct further studies on genetic characteristics and ability to transfer antibiotic resistant genes to other gram-negative bacteria in same ecological conditions.

Funding. The research was not granted any financial support.

Conflict of interests. The authors declare there is no any conflict of interests. 


\section{References}

1. Vietnam food safety risks management: challenges and opportunities. Technical working paper. Hanoi, Vietnam: The World Bank, 2017. Available at: http://documents.worldbank.org/ curated/en/415551490718806138/technical-working-paper (04.01.2020).

2. Wisplinghoff H. Pseudomonas spp., Acinetobacter spp. and Miscellaneous Gram-Negative Bacilli. Infectious Disease, 2017, pp. 1579-1599. DOI: 10.1016/B978-0-7020-6285-8.00181-7

3. Kittinger C., Lipp M., Baumert R., Folli B., Koraimann G., Toplitsch D., Liebmann A., Grisold A. [et al.]. Antibiotic Resistance Patterns of Pseudomonas spp. Isolated from the River Danube. Front. Microbiol, 2016, vol. 3, no. 7, pp. 586. DOI: 10.3389/fmicb.2016.00586

4. Pathogen Safety Data Sheets: Infectious Substances - Pseudomonas spp. Pathogen safety data sheet - infectious substances. The official website of the Government of Canada. Available at: https://www.canada.ca/en/public-health/services/laboratory-biosafety-biosecurity/pathogen-safety-datasheets-risk-assessment/pseudomonas.html (04.01.2020).

5. Odumosu B.T., Ajetunmobi O., Dada-Adegbola H., Odutayo I. Antibiotic susceptibility patternand analysis of plasmid profiles of Pseudomonas aeruginosa from human, animal and plant sources. Springer Plus, 2016, vol. 22, no. 5 (1), pp. 1381. DOI: 10.1186/s40064-016-3073-9

6. Pfeifer Y., Cullik A., Witte W. Resistance to cephalosporins and carbapenems in Gramnegative bacterial pathogens. Int. J. Med. Microbiol, 2010, vol. 300, no. 6, pp. 371-379. DOI: 10.1016/ j.ijmm.2010.04.005

7. Meat and meat products - Enumeration of presumptive Pseudomonas spp. Irish Standard. I.S. EN ISO 13720:2010. 2010, 11 p. Available at: https://infostore.saiglobal.com/preview/ 98699262082.pdf?sku=874780_SAIG_NSAI_NSAI_2079666 (04.01.2020).

8. Weinstein M.P., Patel J.B., Bobenchik A.M., Campeau S., Cullen S.K., Galas M.F., Gold H., Humphries R.M. [et al.]. Performance standards for antimicrobial susceptibility testing. Clinical and Laboratory Standards Institute, 2019, vol. 39, no. 1, pp. 25.

9. WHO Global Foodborne Infections Network (formerly WHO Global Salm-Surv). Laboratory Protocol: «Susceptibility testing of Enterobacteriaceae using disk diffusion». In: S. Karlsmose ed. World Health Organization, Department for Microbiology and Risk Assessment National Food Institute Technical University of Denmark, Copenhagen, 2010, 11 p.

10. Caldera L., Franzetti L., Van Coillie E., De Vos P., Stragier P., De Block J., Heyndrickx M. Identification, enzymatic spoilage characterization and proteolytic activity quantification of Pseudomonas spp. isolated from different foods. Food Microbiology, 2016, vol. 54, pp. 142-153. DOI: 10.1016/j.fm.2015.10.004

11. Thapar P., Garcha S. Incidence and characterization of Pseudomonas species isolated from spoilt fresh produce. Indian Journal of Experimental Biology, 2017, vol. 55, pp. 372-376.

12. Naresh D., Kohler T., Sivalingam P., Van Delden C., Mulaji C.K., Mpiana P.T., Ibelings B.W., Poté J. Antibiotic resistant Pseudomonas spp. in the aquatic environment: A prevalence study under tropical and temperate climate conditions. Water Research, 2017, vol. 115, pp. 256-265. DOI: 10.1016/j.watres.2017.02.058

13. Hamilton A.J., Stagnitti F., Premier R., Boland A.M., Hale G. Quantitative microbial risk assessment models for consumption of raw vegetables irrigated with reclaimed water. Applied and Environmental Microbiology, 2006, vol. 72, no. 5, pp. 3284-3290. DOI: 10.1128/AEM.72.5.32843290.2006

14. Tyrrel S.F., Knox J.W., Weatherhead E.K. Microbiological water quality requirements for salad irrigation in the United Kingdom. Journal of Food Protection, 2006, vol. 69, no. 8, pp. 2029-2035. DOI: $10.4315 / 0362-028 \mathrm{x}-69.8 .2029$

15. Franzetti L., Scarpellini M. Characterisation of Pseudomonas spp. isolated from foods. Annals of Microbiology, 2007, vol. 57, no. 1, pp. 39-47. DOI: 10.1007/BF03175048 
16. Kashina A.-F., Brown P.D. Diversity of Antimicrobial Resistance and Virulence Determinants in Pseudomonas aeruginosa Associated with Fresh Vegetables. International Journal of Microbiology, 2012, no. 6, pp. 426241. DOI: 10.1155/2012/426241

17. Liu D., Tong C. Bacterial community diversity of traditional fermented vegetables in China. LWT - Food Science and Technology, 2017, no. 86, pp. 40-48. DOI: 10.1016/j.lwt.2017.07.040

Nguyen Thanh Trung, Huong Nguyen Minh, Pham Thi Loan, Le Thi Hong Hao, Ta Thi Yen Isolation and identification of $\beta$-lactamase producing Pseudomonas spp. in ready-to-eat raw vegetables. Health Risk Analysis, 2020, no. 1, pp. 101-107. DOI: 10.21668/health.risk/2020.1.11.eng

Received: 09.01.2020.

Accepted: 09.02.2020

Published: 30.03.2020 